\title{
A methodology to promote business development from research outcomes in food science and technology
}

\author{
EduARdo L. CARdoso ${ }^{*}$ \\ ${ }^{\text {a }}$ CBQF - Centro de Biotecnologia e Química Fina - Laboratório Associado, Escola Superior de Biotecnologia, \\ Universidade Católica Portuguesa/Porto, Rua Arquiteto Lobão Vital, Apartado 2511, 4202-401 Porto, Portugal \\ ${ }^{*}$ Corresponding author \\ ecardoso@porto.ucp.pt \\ TEL: +351-225580071 \\ FAX: $+351-225580072$ \\ Received: 15 June 2014; Published online: 18 April 2015 \\ Invited paper from the $3^{\text {rd }}$ International ISEKI_Food Conference - ISEKI_Food 2014 - Bridging Training and \\ Research for Industry and the Wider Community - Food Science and Technology Excellence for a Sustainable \\ Bioeconomy
}

\begin{abstract}
Valorization of knowledge produced in research units has been a major challenge for research universities in contemporary societies. The prevailing forces have led these institutions to develop a "third mission", the facilitation of technology transfer and activity in an entrepreneurial paradigm. Effective management of challenges encountered in the development of academic entrepreneurship and the associated valorization of knowledge produced by universities are major factors to bridge the gap between research and innovation in Europe.

The need to improve the existing institutional knowledge valorization processes, concerning entrepreneurship and business development and the processes required were discussed.

A case study was designed to describe the institutional knowledge valorization process in a food science and technology research unit and a related incubator, during a five year evaluation period that ended in 2012 .

The knowledge valorization processes benefited from the adoption of a structured framework methodology that led to ideas and teams from a business model generation to client development, in parallel, when possible, with an agile product/service development.

Although academic entrepreneurship engagement could be improved, this case study demonstrated that stronger skills development was needed to enable the researcher to be more aware of business development fundamentals and therefore contribute to research decisions and the valorisation of individual and institutional knowledge assets. It was noted that the timing for involvement of companies in the research projects or programs varied with the nature of the research.
\end{abstract}

Keywords: University-industry relations; Research; Valorization of knowledge; Technology transfer; Entrepreneurship; Business development

\section{Introduction}

Valorization of knowledge produced in research units has been a major challenge for research universities in contemporary societies. The pre- vailing forces have led these institutions to develop a "third mission", the facilitation of technology transfer and activity in an entrepreneurial paradigm (Etzkowitz, 2001). In food science and technology, this issue could be argued to be 
more relevant as most businesses are small and medium companies, and there is evidence that effective university-industry collaboration needs "well-equipped" firms (Perkmann et al., 2012). Entrepreneurship has been considered, by different academics (Wennekers \& Thurik, 1999) and policy makers (European Commission, 2008, 2012), as a mean to foster economic development and job creation, particularly relevant in the current social context, but also as an ability to promote a more dynamic, creative, innovative, competitive and sustainable society.

Entrepreneurship can be considered as the process of creating new companies but also as the process of new business development in an existing organizational context. It has also been considered by academia as a useful technology transfer tool.

Overcoming difficulties in the development of academic entrepreneurship and the associated valorization of knowledge produced by universities are included in the required objectives of bridging the gap between research and innovation in Europe (European Commission, 2013).

The main toolbox that is presented to entrepreneurs to exploit knowledge is the "business plan". It is a mean used to consolidate the presentation of the organization of a business idea, to facilitate evaluation that could lead to decisions for further business development. The preparation of a business plan does involve inclusion of technical components that are beyond the skills and interests of academic entrepreneurs, and involve, in an early stage, investment development and planning such as market studies or accounting and financial analysis.

The complexity associated with the various components of a business plan, can become, not only a barrier to the project development, but also a barrier to the investment in intellectual work to structure business ideas based on a specific knowledge (Osterwalder \& Pigneur, 2010).

This context systematically raises the question regarding which methodological tools should be applied to transform an idea into a business, autonomously in a team, supported by local or national structures and programs. This study was designed to identify contributions required to improve the academic knowledge valorization process.
Recognizing the fact that different modes of governance of university-industry interactions should be taken into consideration, especially when small firms are involved (Freitas, Clausen, Fontana, \& Verspagen, 2011), the main question raised was how to improve the existing knowledge valorization process that concerned entrepreneurship and business development in the food sector.

With this backdrop, a case study that would be relevant for the sector was designed. The research analysis was focused on the activity during five years of a research center and an incubator in the area of the Food sector which forms part of a bio-engineer faculty in Portugal.

Relevant contributions to structure approaches to promote entrepreneurship and business development can be identified from a wide range of proposals.

The business model generation proposed by Osterwalder and Pigneur (2010), reduces the centrality of the business plan, and offers systematic steps for an early stage phase, where the key resource for entrepreneurs is intellectual effort. It describes the design or architecture of the value creation and value capturing mechanisms of the business (Teece, 2010). In other words, it describes the rationale of how an organization creates, delivers, and captures value (Osterwalder \& Pigneur, 2010). In the context of research based entrepreneurship and business development, in food science and technology, the business model generation structures and fosters the thinking process "from an idea to a business" and could be a relevant tool to organize the value creation out of research.

A powerful approach to validate business model hypothesis, before capital investments, is proposed by Blank (2005), and, later on, strong structured by Blank and Dorf (2012), the costumer development methodology, articulated with the prior generation of different business models, to search, validate and create customers for a product or a service.

As far as possible, depending on the type of product or service, the adoption of principles of an agile product or service development (Ries, 2011), could lead, through intense interactions with costumers, to better adequate solutions for the needs or opportunities identified in the mar- 
ket. This should be a parallel process with the costumer development process, focused on: individuals and interactions, prototypes, costumer collaboration, and responding to change.

\section{Materials and Methods}

\subsection{The case study methodology}

The case study as a research methodology has appropriate characteristics to fit the objectives of the defined study and to structure the design of the research, which seeks to explain interactions between multiple factors that manifest themselves in a real context being developed, within a well-defined occurrence, both in terms of the organizational framework as well as in the time frame, and with a reduced control of the researcher (Yin, 1994; Miles \& Huberman, 1994). The case study should be able to involve the various actors of the innovation process, consider the various points of view and allow an analysis of data from multiple perspectives (Tellis, 1997). It is an empirical method of inquiry to investigate a contemporary phenomenon in its real context of occurrence, especially interesting when the boundaries between phenomenon and context are not clearly evident (Yin, 1994).

It responds to the need of understanding a social phenomenon, clarifying reasons, characterizing the processes and identifying drawbacks, improvements, and potential implications.

\subsection{The case study description}

The case study is described as the institutional knowledge valorization process based on a research unit and a related incubator, both focused on food science and technology, during a five year evaluation period, between 2008 and 2012.

The Research Center: CBQF - ESB-UCP (Porto-Portugal)

Area: Food, Nutrition, Health Being and Environment

Key indicators in the period 2008-2012: 100 researchers, 362 papers, 14 patents, $38 \mathrm{PhD}$ completed, 28 industry research contracts and projects, and another 52 research projects.

www.esb.ucp.pt/cbqf
The Incubator: BioSpin Incubator (PortoPortugal)

Area: Bio-based economy

Key indicators in the period 2008-2012: Preincubation projects - 5 actual (3 drop-outs); Incubation of start-up companies - 8 actual (5 out in the market, 1 drop-out); Spin-offs: 4 (1 closed).

www.spinlogic.pt

\subsection{Instruments}

A set of instruments were designed to collect data. Interviews with key staff involved, observation and field notes from, research project presentations, business project presentations, coordinating meetings, training sessions, coaching services, seminars and networking events. Relevant documentation was also collected in the form of activity plans and reports, management reports, evaluation reports, project portfolios, project proposals and business presentations.

\subsection{Data analysis}

Data collected was organized based on significant data units and submitted to a content analysis approach that allowed the identification of major underlying concepts relevant to understanding the institutional knowledge valorization process based on the research unit and the related incubator, and the potential drawbacks and improvements suggested.

\section{Results and Discussion}

When a business idea associated with the exploitation of knowledge already has a patent submitted for intellectual property (IP) rights protection, the university option was to collaborate with an institutional partner that offers a structured and financed pathway for knowledge valorisation, if the project was considered to be "high tech-high growth". The partner was COTEC - Portugal (there are similar structures in Spain and Italy) which annually organize the COHiTEC training program, the entry point to its full pathway (www.cotec.pt). Neither the university, nor the research center, have any 
contribution to the followed methodology. This option, attracted researchers (one team of researchers per year participated in the program) but high levels of drop-outs were reported in different phases of the pathway (four dropouts out of five) and ended with long processes that did not produce numerous projects(it took more than five years for one project to became a start-up in 2013, with a risk capital investment of 1.4 Million Euro). The outcomes of research teams were, in general, considered by this partner, as too early-stage and not sufficiently business oriented to attract positive evaluation by investors, companies, and even for the IP valorization pipeline.

Competencies of research teams were, in general, also considered by the same actor, too weak in what concerns: collaboration, "coopetition" (to cooperate and compete simultaneously), communication, social awareness, initiative and entrepreneurship. Those skills are often associated with added-value for social development (Tapscott \& Williams, 2006). The approach followed was to team researchers with MBA course participants in search for well-balanced teams in what concerns competencies.

Most business ideas and projects, which used the Incubator as a pathway to markets, showed low or medium knowledge intensity and some of them were either based on or included services on their value proposition to prospected costumers. Researchers' based project teams were, in most cases, based on former students from food science and technology BSc and MSc programs. The BioSpin - food sector incubator offered two organized phases for the teams, the pre-incubation phase (six to twelve months) and the incubation phase (one to three years).

The proposed methodologies for the business project development were designed, from the period of analysis start and in order to overcome the need of a business plan, to build a business case based on significant methodologies to create value around ideas, knowledge, and skills of researchers and teams.

The methodological approaches that were proposed ended with a starting point following fundamentals of the generation of business models (Osterwalder \& Pigneur, 2010) that, being deepened, should be able to be validated or improved by customer development techniques (Blank \& Dorf, 2012) that structured a search effort for customer discovery and validation before the company's execution steps.

The business model constructed was well discussed in the literature (Lurie, 2012), sometimes with remarks related to the way marketing or strategy are represented or considered. This concept is actively used in a variety of management and organizational practices such as innovation, strategy, new venture, franchising, internationalization and organizational design (Teece, 2010; Zott \& Amit, 2008; Osterwalder \& Pigneur, 2010).

When possible the process of design and development of products or services recommended to engage in an agile strategy were those that could fit identified needs or opportunities (Ries, 2011). Agile methodologies are, in particular, adequate to offer value in the software industry, but the key concepts can enlighten the thinking and the practice in other sectors; such is the food sector and the bio-economy area.

Only some of the observed projects followed the key milestones of the methodology proposed, so significant results could be expected if teams were able to dedicate much more time and effort to the start-up steps requesting more intellectual than financial investment. Results suggest that the significant effort required to plan a for business project and assemble the needed structures achieved by intensive engagement in programs such as boot camps, entrepreneurship weekends, and others that could be relevant for other objectives as networking, exposure, enlightenment, and motivation.

There is also evidence that additional external input is needed for the projects to reach a higher level of readiness required for start-up. There was interesting examples of the role of business consultants, business angels and mentors, which help some projects to get stronger positions in market testing and facing investors.

The large majority of researchers (more than $80 \%$ ), in $\mathrm{PhD}$ programs, Post-Doctoral programs, or Project Contracted Fellowships, did not become involved in any observed process of the institutional knowledge valorisation process. PhD projects, and also Post-Doctoral projects, were claimed to be driven by scientific relevance 
and merit but not, in general, by the needs and wants of participating companies.

Regarding industrial co-promoted research funded projects; there was no evidence to suggest that better company involvement would produce significant results in terms of business innovation and development. The research projects designed and developed in co-promotion with companies followed, in the national Portuguese system of incentives in innovation, a model that did not seem to contribute to the best knowledge valorization. The project ownership was not clear, as both parts had to co-finance the project, with space for both the company and for the university objectives, and, it seemed, that in most cases there were two projects being undertaken: one from the university and another from the company.

Senior researchers stated that questions raised by the companies were usually less interesting from a research perspective, as they tended to be more applied and less fundamental.

Results also suggest that, from research work, potential applications were expected. There was a need for another level of university-industry interaction that would allow for the conditions of an early identification of companies or investors in the existing business ecosystem. This effort was often tried later after research projects were completed or patents submitted, with stronger restrictions in time and budget to achieve suitable partners.

It is also understandable that a significant number of patents would expire or possibly, have restricted exposure at national level, as evidence of the research center's inventive capacity but without any chance of valorization or commercialization.

\section{Conclusions}

The institutional knowledge valorization processes conducted through entrepreneurship or business development pathways should, as identified, benefit from the adoption of a structured framework methodology that would lead ideas and teams from a business model generation to client development, in parallel, when possible, with an agile product/service development.
Although academic entrepreneurship engagement could be improved, this case study has shown evidence that stronger skills development should be followed, which would enable researchers to have greater awareness of business development fundamentals and also contribute to research decisions and for the valorisation of individual and institutional knowledge actives. Certainly, researchers do not need to be business managers, but some skills would raise the value of their knowledgeable assets like "wikiskills": collaboration, "coopetition", social awareness, initiative and entrepreneurship (Wikinomics Project, 2013).

When research is applied, such that it is more likely to generate innovation, there were different individual and institutional reasons for the early involvement of companies in the research projects or programs.

The involvement design could have contextual relevant issues, but some concrete proposals could be submitted from the results observed:

- Presentation of the research plan (for a $\mathrm{PhD}$ or a Pos-Doctoral project) to a company or a cluster at 6 to 12 months;

- Annual presentation of the research project achievements to a company or a cluster;

- Presentation, in the second half of a research project, of key achievements to potential investors. This kind of exposure could be as controlled and as adequate to each contextual condition as possible but it would be expected to promote not only a better incorporation of business needs but also a better awareness from the industry side to research achievements including the identification of the first potential clients for the knowledge produced by researchers, time reduction to market, and to create much better conditions to support decisions about IP protection.

This kind of formal approach could build the basis for a closer and earlier articulation between research, industry and investors.

Building consortiums for co-promoted research projects, even with adequate financing models, 
should be focused on the integration of a business development in any applied research plan, on the work packages that are related to demonstration, exploitation and dissemination, to be more market oriented. It also seemed that a key role should be attributed to medium and large companies on leading industry participation in research projects, even to enhance the participation of smallest companies.

Although no specific evidence was collected and reported, the fact that most of the researchers were not active in the institutional knowledge valorisation processes, may indicate that other approaches to IP governance, including IP management, should be considered and acknowledged, focused on individual interactions in the university-industry relations. This could include the ability to exploit open innovation with potential benefits for researchers, institutions and society, and the ability to innovate by collaboration with business professionals and within the entrepreneurial ecosystem, by "coopetition" in the market, by co-creation with customers, following other alternative approaches to the institutional traditional governance.

\section{Acknowledgements}

We acknowledge support from the Wikinomics Project funded under the LifeLong Program of the European Commission (2013-1CH1-LEO0500869).

Additional support was provided by the Biotechnology Faculty of the Portuguese Catholic University in Porto.

\section{References}

Blank, S. (2005). The four steps to the epiphany. Pescadero: K\&S Ranch.

Blank, S. G. \& Dorf, B. (2012). The startup owner's manual: The step-by-step guide for building a great company. Pescadero: K\&S Ranch Press.

Etzkowitz, H. (2001). The second academic revolution and the rise of entrepreneurial science. IEEE Technology and Society Magazine, 20(2), 18-29. doi:10.1109/44.948843
European Commission. (2008). Think Small First: A 'Small Business Act' for Europe. Brussels: EC.

European Commission. (2012). Entrepreneurship 2020 Action Plan. Brussels: EC.

European Commission. (2013). Horizon 2020: research and innovation to boost growth and jobs in Europe. Brussels: EC.

Freitas, I. M. B., Clausen, T. H., Fontana, R., \& Verspagen, B. (2011). Formal and informal external linkages and firms' innovative strategies. A cross-country comparison. Journal of Evolutionary Economics, 21 (1), 91-119. doi:10 . 1007 / s00191- 010 0188-y

Lurie, M. (2012). What is a business model? A new approach. Blue Mine Group.

Miles, M. B. \& Huberman, A. M. (1994). Qualitative data analysis: An expanded sourcebook. Sage.

Osterwalder, A. \& Pigneur, Y. (2010). Business Model Generation: A Handbook For Visionaries, Game Changers, and Challengers Author: Alexander Osterwalder, Yves. Wiley.

Perkmann, M., Tartari, V., McKelvey, M., Autio, E., Brostrom, A., D'Este, P., ... Sobrero, M. (2012). Academic engagement and commercialisation: A review of the literature on university-industry relations. Research Policy, 42(2), 423-442. doi:10.1016/j.respol. 2012.09.007

Ries, E. (2011). The lean startup: How today's entrepreneurs use continuous innovation to create radically successful businesses. U.S.: Crown Business.

Tapscott, D. \& Williams, A. (2006). Wikinomics: How mass collaboration changes everything. London: Atlantic Books.

Teece, D. J. (2010). Business Models, Business Strategy and Innovation. Long Range Planning, 43(2-3, SI), 172-194. doi:10.1016/j. lrp.2009.07.003

Tellis, W. (1997). Application of a case study methodology. The qualitative report, 3(3), 1-17. Retrieved from http://www. nova. edu/ssss/QR/QR3-3/tellis2.html

Wennekers, S. \& Thurik, R. (1999). Linking entrepreneurship and economic growth. 
Small Business Economics, 13(1), 27-55. doi:10.1023/A:1008063200484

Wikinomics Project. (2013). Wikinomics concept. Retrieved from http://wikiskills.net/ wikinomics

Yin, R. (1994). Case study research: Design and methods. Beverly Hills. CA: Sage publishing.

Zott, C. \& Amit, R. (2008). The fit between product market strategy and business model: Implications for firm performance. Strategic Management Journal, 29(1), 1-26. doi:10.1002/smj.642 